\title{
Molecular Ions of Ionic Liquids in the Gas Phase
}

\author{
Jürgen H. Gross \\ Institute of Organic Chemistry, University of Heidelberg, Heidelberg, Germany
}

Ionic liquids form neutral ion pairs (CA) upon evaporation. The softness of the gas-phase ionization of field ionization has been used to generate "molecular ions," $\mathrm{CA}^{+}{ }^{\circ}$, of ionic liquids, most probably by neutralization of the anion. In detail, 1-ethyl-3-methylimidazoliumthiocyanate, $\left[\mathrm{C}_{6} \mathrm{H}_{11} \mathrm{~N}_{2}\right]^{+}[\mathrm{SCN}]^{-}$, 1-butyl-3-methylimidazolium-tricyanomethide, $\left[\mathrm{C}_{8} \mathrm{H}_{15} \mathrm{~N}_{2}\right]^{+}$ $\left[\mathrm{C}_{4} \mathrm{~N}_{3}\right]^{-}, N$-butyl-3-methylpyridinium-dicyanamide, $\left[\mathrm{C}_{10} \mathrm{H}_{16} \mathrm{~N}\right]^{+}\left[\mathrm{C}_{2} \mathrm{~N}_{3}\right]^{-}$, and 1-butyl-1methylpyrrolidinium-bis[(trifluormethyl)sulfonyl]amide, $\left[\mathrm{C}_{9} \mathrm{H}_{20} \mathrm{~N}^{+}\left[\mathrm{C}_{2} \mathrm{~F}_{6} \mathrm{NO}_{4} \mathrm{~S}_{2}\right]^{-}\right.$were used. The assignment as $\mathrm{CA}^{+}$ions, which has been confirmed by accurate mass measurements and misassignments due to thermal decomposition of the ionic liquids, has been ruled out by field desorption and electrospray ionization mass spectrometry of the residues. (J Am Soc Mass Spectrom 2008, 19, 1347-1352) (C 2008 American Society for Mass Spectrometry

$\mathrm{I}$ onic liquids (ILs) represent salts consisting of an organic cation $\left(\mathrm{C}^{+}\right)$and frequently also of an organic anion $\left(\mathrm{A}^{-}\right)$. Their classification as ILs is based on a melting point normally below room temperature, but at least $<100^{\circ} \mathrm{C}$. Initially, it was assumed that their vapor pressure should be equal or close to zero, or at least too low to be determined experimentally. Still, these properties are regarded as basic characteristics of ILs determining their application as highly polar solvents and mediators of chemical reactions [1-6].

In 2006, Earle et al. demonstrated that 1-alkyl-3methylimidazolium bis[(trifluormethyl)sulfonyl]amides may in fact be vaporized in vacuum and can even be separated by distillation [7]. From these experiments directly arose the question about the nature of the gas-phase species involved. ILs were supposed to form ion pairs (CA) in the gas phase, an assumption that may by now be regarded as experimentally verified $[8,9]$.

Electron ionization (EI) mass spectra of 1-alkyl-3methylimidazolium bis[(trifluormethyl)sulfonyl]amides showed an intensive signal corresponding to $\mathrm{C}^{+}$and some fragment ions arising thereof. A hint of the anion is presented by detection of the molecular ion of the protonated anion $[\mathrm{A}+\mathrm{H}]^{+\bullet}$, which was observed at very low intensity. The authors assumed the ionization of an ion pair CA by a primary electron and the subsequent spontaneous decay of the ionized ion pair, $[\mathrm{CA}]^{+}$, thereby forming $\mathrm{C}^{+}$and $\mathrm{A}^{*}$ (Scheme 1) [10].

Further support for ion-pair formation came from ion cyclotron resonance mass spectrometric experiments where no ions could be detected upon direct evaporation of ILs into the ion cyclotron resonance (ICR) cell. However, cations were observed in positive-

Address reprint requests to Dr. Jürgen $\mathrm{H}$. Gross, University of Heidelberg, Institute of Organic Chemistry, Im Neuenheimer Feld 270, 69120 Heidelberg, Germany. E-mail: juergen.gross@oci.uni-heidelberg.de ion mode and anions in negative ion-mode, respectively, after energetic electrons were admitted into the ICR cell to energize the gas-phase particles [11]. These results are in accordance with the previously cited electron impact (EI) experiments. Using atmospheric pressure chemical ionization (APCI) DaSilveira et al. also concluded that ion pairs should exist in the gas phase. In addition to the isolated cations and anions, they were able to detect $\left[\mathrm{C}_{2} \mathrm{~A}\right]^{+}$in positive-ion APCI and $\left[\mathrm{CA}_{2}\right]^{-}$as well as $\left[\mathrm{C}_{2} \mathrm{~A}_{3}\right]^{-}$cluster ions in negativeion APCI [12]. A similar appearance of the mass spectra is obtained, when so-called desorption methods, i.e., ionization techniques delivering ions directly from the condensed phase, are used. Under these conditions, the ILs either form highly abundant $\mathrm{C}^{+}$ions accompanied by a series of positive cluster ions of the general formula $\left[\mathrm{C}_{n} \mathrm{~A}_{n-1}\right]^{+}$or $\mathrm{A}^{-}$and the corresponding negative cluster ion series $\left[\mathrm{A}_{n} \mathrm{C}_{n-1}\right]^{-}$. Which of these series is observed is solely determined by the polarity of the extraction voltage. Such observations were made by fast atom bombardment (FAB) [13], laser desorption/ionization (LDI) [14], matrix-assisted laser desorption/ ionization (MALDI) [14-16], electrospray ionization (ESI) [17-20], and field desorption (FD) [21]. However, none of these ionization methods delivered the ionized ion pair, the "molecular ion" $\mathrm{CA}^{+*}$, of an IL that would yield further support for the ionization mechanism shown in Scheme 1.

Field ionization (FI) presents an extremely soft method for the generation of ions from gas-phase molecules [22, 23]. Because of the requirement of external evaporation of the analyte before its ionization in the gas phase, in practical work, FI was soon superseded by FD, where the analyte is applied directly onto the surface of the field emitter [24-26]. Since the advent of liquid injection field desorption/ionization (LIFDI) [27] FD is gaining new relevance. In FI, molecules are 


\section{$[\mathrm{CA}]+\mathrm{e}^{-} \longrightarrow[\mathrm{CA}]^{+\cdot}+2 \mathrm{e}^{-}$

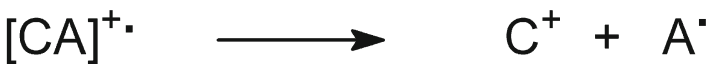 \\ Scheme 1}

ionized under the influence of a strong electric field $\left(10-20 \mathrm{~V} \mathrm{~nm}^{-1}\right)$, which is able to retract an electron from the neutral. Different from EI, removal of the electron is not accompanied by the transfer of large amounts of energy. For example, FI enables the generation of molecular ions of large aliphatic hydrocarbons with no or little fragmentation [28-30]. Vice versa, the chances to observe a molecular ion by means of FI are very high even when it exists only within an extremely shallow potential well.

This softness of gas-phase ionization by FI could now be used to detect the "molecular ions," $\mathrm{CA}^{+}$, of some ILs by mass spectrometry. In detail, 1-ethyl-3methylimidazolium-thiocyanate, $\left[\mathrm{C}_{6} \mathrm{H}_{11} \mathrm{~N}_{2}\right]^{+}[\mathrm{SCN}]^{-}$ (1), 1-butyl-3-methylimidazolium-tricyanomethide, $\left[\mathrm{C}_{8} \mathrm{H}_{15} \mathrm{~N}_{2}\right]^{+}\left[\mathrm{C}_{4} \mathrm{~N}_{3}\right]^{-}$(2), N-butyl-3-methylpyridiniumdicyanamide, $\left[\mathrm{C}_{10} \mathrm{H}_{16} \mathrm{~N}\right]^{+}\left[\mathrm{C}_{2} \mathrm{~N}_{3}\right]^{-}$(3), and 1-butyl-1methylpyrrolidinium-bis[(trifluormethyl)sulfonyl]amide, $\left[\mathrm{C}_{9} \mathrm{H}_{20} \mathrm{~N}\right]^{+}\left[\mathrm{C}_{2} \mathrm{~F}_{6} \mathrm{NO}_{4} \mathrm{~S}_{2}\right]^{-}$(4) were used. The last-mentioned IL 4 belonged to the group of ILs that could be distilled.

\section{Experimental}

All ILs used are commercially available (Merck KGaA, Darmstadt, Germany). They were used as neat compounds as supplied by the manufacturer. Their identity and purity had also been confirmed in a previous study by LIFDI-MS [21].
For field ionization, the FI/FD ion source of a double-focusing JMS-700 magnetic sector instrument (JEOL, Tokyo, Japan) was heated to $230-250{ }^{\circ} \mathrm{C}$. About $0.2 \mu \mathrm{l}$ of the IL were placed into a glass sample vial (MS Wil, Wil, Switzerland) and evaporated directly into the ionization volume by means of a direct insertion probe (DIP) that was heated at a rate of $64^{\circ} \mathrm{C} / \mathrm{min}$ from ambient temperature to $300-450^{\circ} \mathrm{C}$. For FI use optimized $5 \mu \mathrm{m}$ activated field emitters (Linden CMS, Leeste, Germany) were used at an emitter heating current (EHC) of $10 \mathrm{~mA}$. FD emitters based on $13 \mu \mathrm{m}$ wires at an EHC of $15 \mathrm{~mA}$ basically allowed us to obtain the same results, but overall delivered lower signal intensity (cf. supplementary material, which can be found in the online version of this article). The emitters were set to $12.0 \mathrm{kV}$ high voltage relative to the counter electrode. For full scan spectra the magnet was scanned from $\mathrm{m} / \mathrm{z} 50$ to 800 at a resolving power of 1000 in 5-8 $\mathrm{s}$ per scan cycle.

For accurate mass measurements of the $\mathrm{CA}^{+} \cdot$ ions, the voltage of the electrostatic sector $U_{\mathrm{e}}$ was scanned proportional to the accelerating voltage $U_{\mathrm{a}}$, i.e., a scan at constant $U_{\mathrm{e}} / U_{\mathrm{a}}$ was used. The resolving power was then adjusted to 2500 and perfluorokerosene (PFK) for internal mass calibration was admitted from the reservoir inlet via a needle valve. The $m / z 210-275$ range was scanned at $7 \mathrm{~s}$ per cycle and several scans were added before internal calibration. In one case (cf. Figure 3) a magnet scan was used instead, whereas the other parameters remained unaltered.

Helium was used as collision gas for collision-induced dissociation (CID) spectra. It was admitted to the collision cell in the first field-free region of the instrument, which was set to a resolving power of 800 and scanned in $5-8 \mathrm{~s}$ per cycle at constant $B / E$.

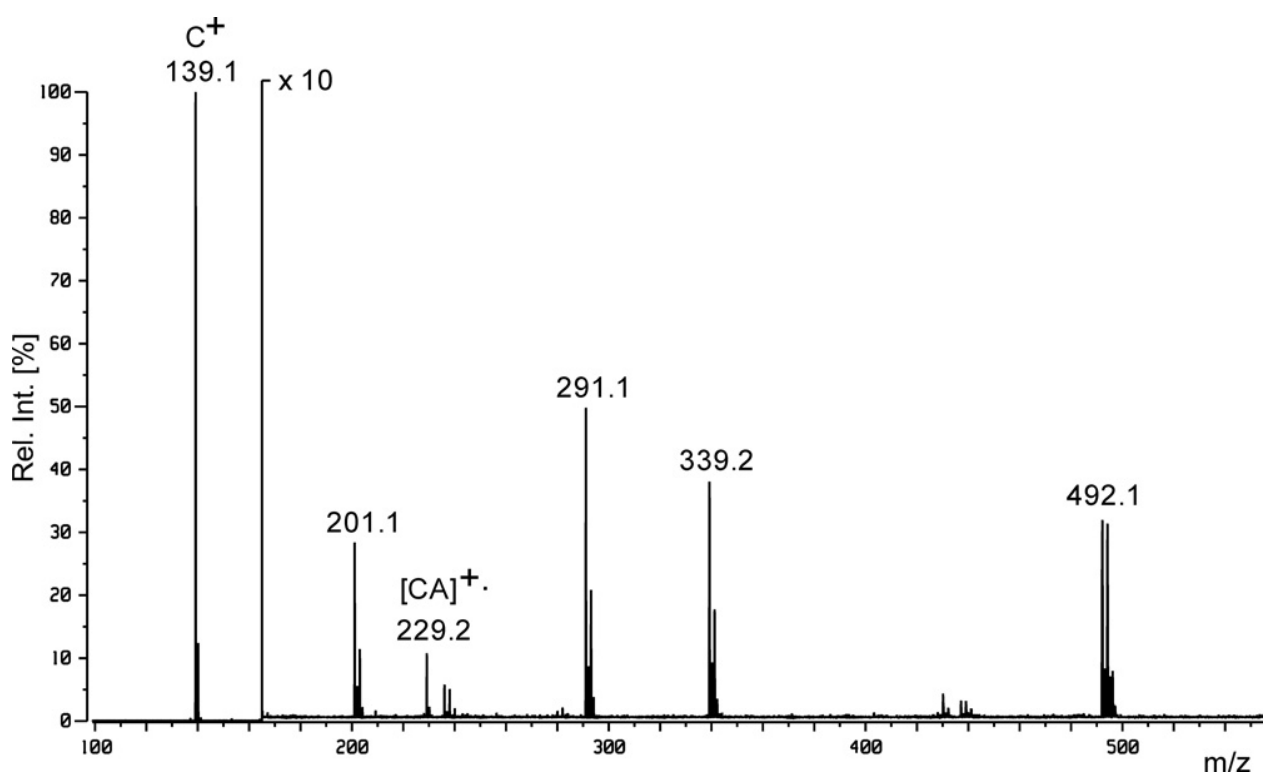

Figure 1. FI mass spectrum of 2 . Above $m / z 165$ the intensity is scaled up by a factor of 10 . The "molecular ion" of $\mathbf{2}$ is displayed at $\mathrm{m} / \mathrm{z} 229.2$. The base peak at $\mathrm{m} / \mathrm{z} 139.1$ is caused by the cation of the IL. 


\section{Results and Discussion}

The cation $\mathrm{C}^{+}$gives rise to base peak in the FI spectra of 1-4, whereas all other signals appear with significantly lower intensity. Different from FD conditions, the cation is not accompanied by $\left[\mathrm{C}_{n} \mathrm{~A}_{n-1}\right]^{+}$cluster ions. The only other signals that are observed might result from minor impurities or products of thermal decomposition.

The FI spectrum of 2 clearly exhibits the "molecular ion" at $\mathrm{m} / \mathrm{z} 229.2$ (Figure 1). The base peak of the spectrum at $\mathrm{m} / \mathrm{z} 139.1$ is caused by the cation of the IL.

Typically, the "molecular ions" require a probe temperature of about $250{ }^{\circ} \mathrm{C}$ to occur. Their intensity further increases upon heating to $350-450{ }^{\circ} \mathrm{C}$. Resulting from the minimal volatility of the ILs and the high probe temperature compared to the temperature of the ion source, condensation of ILs could not fully be avoided and caused signals to persist even after removal of the direct insertion probe. Consequently, only the first spectrum within a series of measurements allowed for the acquisition of an FI spectrum free of superimpositions (cf. supplementary material). On the other hand, ionic compositions were then observed that could be interpreted in terms of combinations of ions between the actual sample and previous one(s). Intentional mixing of these ILs then allowed for the reproduction of these signals at clearly higher intensity.

Determination of the accurate masses delivered proof of the assignment as $\mathrm{CA}^{+} \cdot$ ions. The molecular
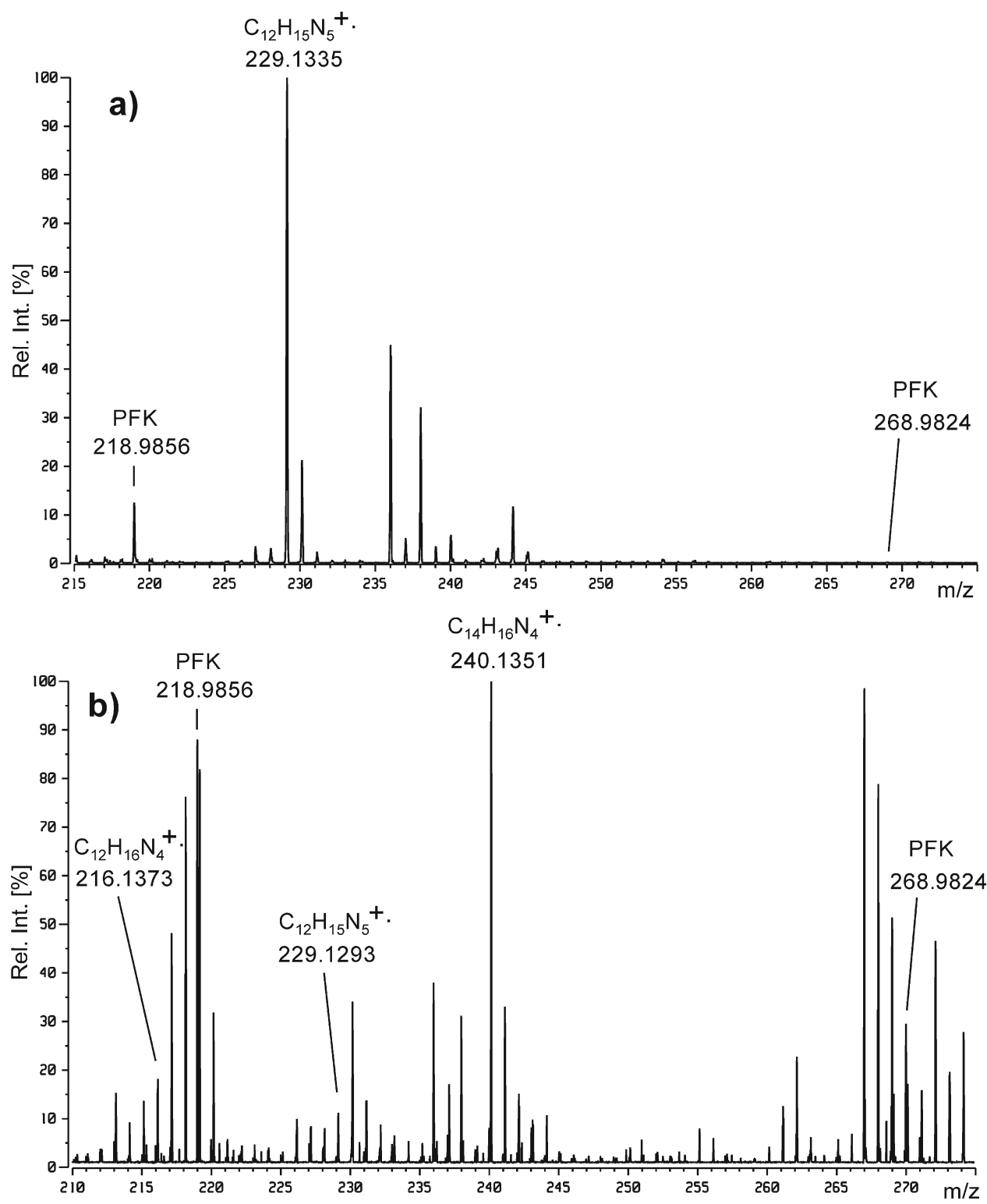

Figure 2. (a) Determination of the accurate mass of $\mathbf{2}$ in FI mode via internal calibration with PFK. The "molecular ions" delivered the most abundant analyte ion in this $\mathrm{m} / \mathrm{z}$ range. (b) Determination of the accurate masses from a mixture of ILs 2 and 3 . The ion formed by attachment of tricyanomethide to a cation is preferred. Both FI spectra were obtained by scanning at constant $U_{\mathrm{a}} / U_{\mathrm{e}}$. 
Table 1. Collection of analytes, "molecular ions," and accurate masses

\begin{tabular}{llccc}
\hline & \multicolumn{2}{c}{ Detected combination } & & \\
\cline { 2 - 4 } Analyte & {$[\mathrm{CA}]^{+\cdot}$} & Formula & Measured $\mathrm{m} / \mathrm{z}$ & Calculated $\mathrm{m} / \mathrm{z}$ \\
\hline \hline $1+2^{\mathrm{a}}$ & {$\left[\mathrm{C}_{6} \mathrm{H}_{11} \mathrm{~N}_{2} \mathrm{C}_{4} \mathrm{~N}_{3}\right]^{+\cdot}$} & $\mathrm{C}_{10} \mathrm{H}_{11} \mathrm{~N}_{5}{ }^{+\cdot}$ & 201.0988 & 201.1009 \\
& {$\left[\mathrm{C}_{8} \mathrm{H}_{15} \mathrm{~N}_{2} \mathrm{C}_{4} \mathrm{~N}_{3}\right]^{+\cdot}$} & $\mathrm{C}_{12} \mathrm{H}_{15} \mathrm{~N}_{5}^{+\cdot}$ & 229.1327 & 229.1322 \\
2 & {$\left[\mathrm{C}_{8} \mathrm{H}_{15} \mathrm{~N}_{2} \mathrm{C}_{4} \mathrm{~N}_{3}\right]^{+\cdot}$} & $\mathrm{C}_{12} \mathrm{H}_{15} \mathrm{~N}_{5}^{+\cdot}$ & 229.1320 & 229.1322 \\
$2+3$ & {$\left[\mathrm{C}_{10} \mathrm{H}_{16} \mathrm{~N} \mathrm{C}_{2} \mathrm{~N}_{3}\right]^{+\cdot}$} & $\mathrm{C}_{12} \mathrm{H}_{16} \mathrm{~N}_{4}^{+\cdot}$ & 216.1373 & 216.1370 \\
& {$\left[\mathrm{C}_{8} \mathrm{H}_{15} \mathrm{~N}_{2} \mathrm{C}_{4} \mathrm{~N}_{3}\right]^{+\cdot}$} & $\mathrm{C}_{12} \mathrm{H}_{15} \mathrm{~N}_{5}^{++}$ & 229.1293 & 229.1322 \\
& {$\left[\mathrm{C}_{10} \mathrm{H}_{16} \mathrm{~N} \mathrm{C}_{4} \mathrm{~N}_{3}\right]^{+\cdot}$} & $\mathrm{C}_{14} \mathrm{H}_{16} \mathrm{~N}_{4}^{+\cdot}$ & 240.1351 & 240.1370 \\
$2+4$ & {$\left[\mathrm{C}_{8} \mathrm{H}_{15} \mathrm{~N}_{2} \mathrm{C}_{4} \mathrm{~N}_{3}\right]^{+\cdot}$} & $\mathrm{C}_{12} \mathrm{H}_{15} \mathrm{~N}_{5}^{+\cdot}$ & 229.1321 & 229.1322 \\
& {$\left[\mathrm{C}_{9} \mathrm{H}_{20} \mathrm{~N} \mathrm{C}_{4} \mathrm{~N}_{3}\right]^{+\cdot}$} & $\mathrm{C}_{13} \mathrm{H}_{20} \mathrm{~N}_{4}^{+\cdot}$ & 232.1664 & 232.1682 \\
\hline
\end{tabular}

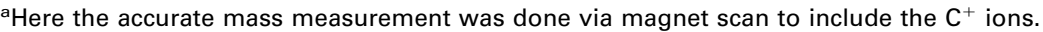

formulas could be verified not only in the FI spectrum of pure 2 but also from mixtures with other ILs (Figure 2 and Table 1).

The evaporation of ILs is inevitably accompanied by some degree of decomposition. After the measurement, this is obvious by the sample's change from colorless to some brownish color of the residual material in the sample vial. For example, in the FI spectrum of a mixture of $\mathbf{1}$ and $\mathbf{2}$ some ions were observed that are most probably attributable to thermal reactions. The peaks at $\mathrm{m} / \mathrm{z} 142$ and 170 present in addition to the "molecular ions" could be assigned to $[\mathrm{C}-\mathrm{H}+\mathrm{S}]^{+}$• ions, the corresponding molecular formulas of which were also determined by accurate mass measurements (Figure 3).

Thus, there might be a chance that decomposition products-incidentally having the same elemental compositions as those of the presumed molecular ionswere detected instead. Therefore, FD mass spectra of the residues were recorded. Only in case of the combi- nation $2+3$ some very small peaks $(\sim 0.1 \%$ relative intensity) were detected at $\mathrm{m} / \mathrm{z} 230$ and 241 in addition to the ions normally observed from ILs under FD conditions. In principle, those ions at $\mathrm{m} / \mathrm{z} 230$ and 241 might be assigned as $[\mathrm{M}+\mathrm{H}]^{+}$ions of such interfering molecules. The experiment was therefore repeated and the residue was subsequently subjected to positive-ion electrospray Fourier transform ion cyclotron resonance mass spectrometry (ESI-FT-ICR-MS). This way, those ions could unequivocally be identified as $\left[\mathrm{C}_{14} \mathrm{H}_{20} \mathrm{~N}_{3}\right]^{+}$ and $\left[\mathrm{C}_{16} \mathrm{H}_{21} \mathrm{~N}_{2}\right]^{+}$with relative mass errors of $<0.5 \mathrm{ppm}$. Incidental coincidence of the "molecular ions" of ILs detected by FI with isomeric molecular decomposition products can therefore be ruled out (cf. supplementary material).

From the pool of ILs that had previously been studied by LIFDI [21], exclusively tricyanomthide was able to effectively cause the formation of "molecular ions." When dicyanamide and thiocyanate were used instead, the corresponding ions were observed, only

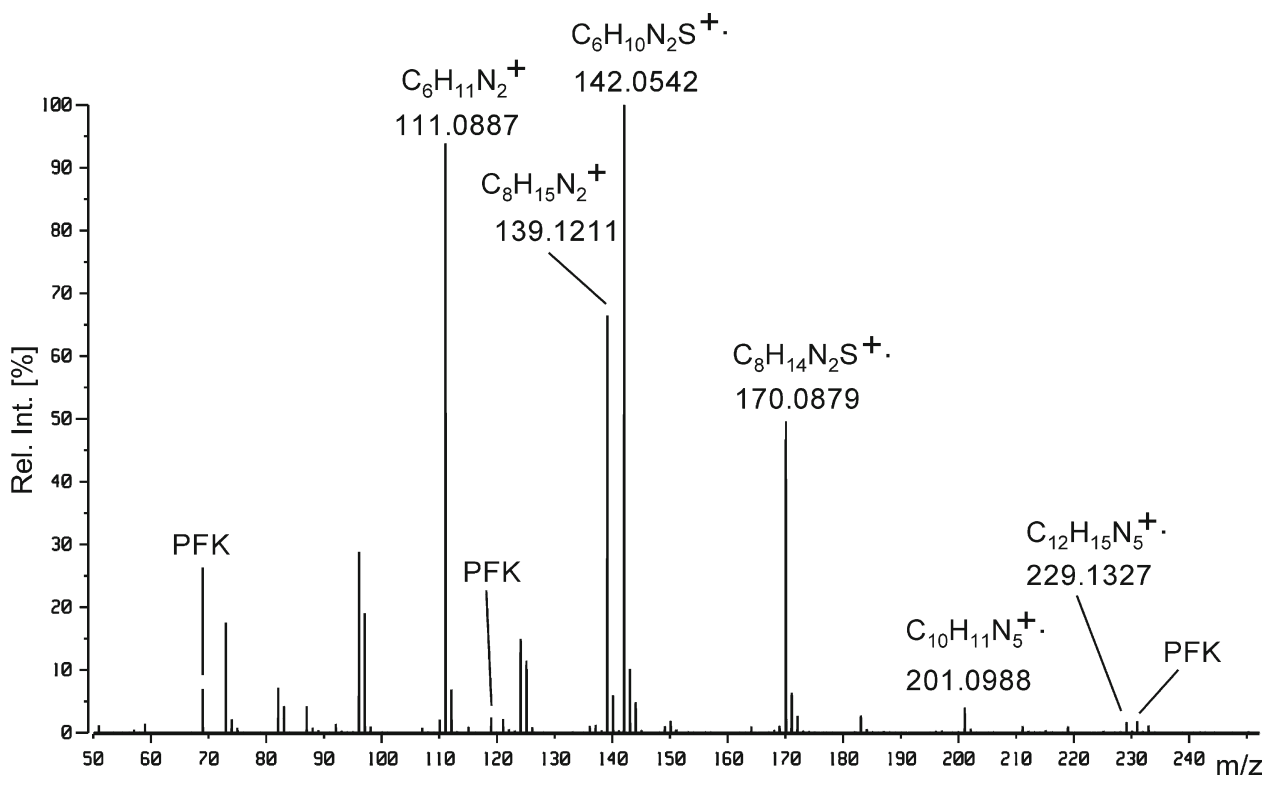

Figure 3. Both "molecular ions" are observed at $m / z 201$ and 229 upon mixing of $\mathbf{1}$ and $\mathbf{2}$ in the vial. In addition, the composition of the by-products $\left[\mathrm{C}-\mathrm{H}+\mathrm{S}^{+}{ }^{\bullet}\right.$ at $\mathrm{m} / \mathrm{z} 142$ and 170 that are most probably formed by thermal reactions and of both $\mathrm{C}^{+}$ions can be determined. Here, this is the only HR-FI spectrum obtained by magnet scanning. Prominent PFK signals are labeled as such. 


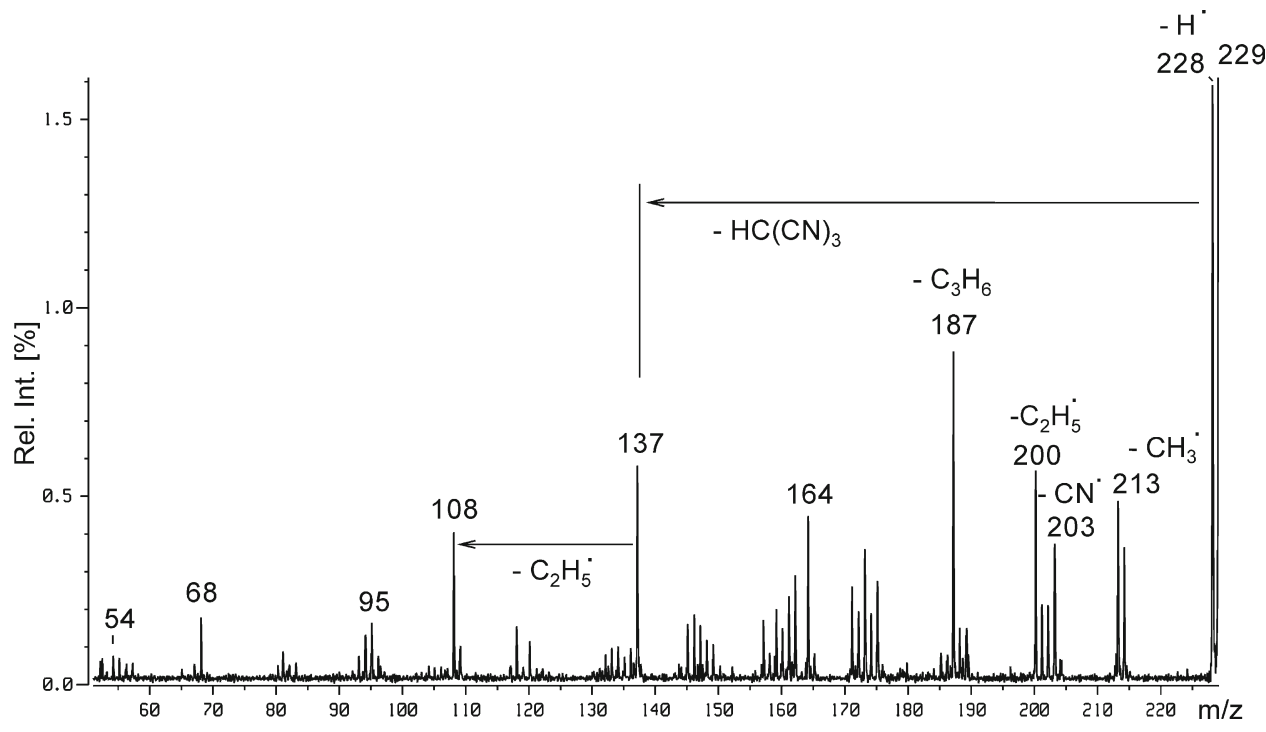

Figure 4. CID spectrum of the $[\mathrm{CA}]^{+}$ion from IL $2, m / z 229$. The intensity scale is expanded to show the peak ascribed to $[\mathrm{CA}-\mathrm{H}]^{+}, m / z 228$, at full size.

with much lower abundance. From bis[(trifluormethyl)sulfonyl]amide "molecular ions" were no longer observed. The importance of the soft tricyanonomethide anion can be deduced from the fact that mixtures of ILs preferably yielded those $[\mathrm{CA}]^{+}{ }^{\circ}$ ions where the cations formed ion pairs with tricyanomethide, whereas combinations with competing anions played a less important role.

It immediately follows from these observations that ionization-more accurately neutralization of the anion by electron abstraction - can most easily be achieved at the tricyanomethide. Consequently, a distonic ion [31, 32] is formed upon FI of the ion pair. If one excludes the existence of a covalent bond, i.e., generation of $[\mathrm{C}-\mathrm{A}]^{+}$, the product of FI rather corresponds to a cation-radical complex, $\left[\mathrm{C}^{+} \mathrm{A}^{\bullet}\right]$. Cation-radical complexes play a role during the fragmentation of ethylpropylthioether molecular ions, for example [33].

CID mass spectra of the $[\mathrm{CA}]^{+}$ions indicate that these ions exhibit surprisingly high stability because the decomposition pathway, as expected according to Scheme 1, is not observed. Instead, they behave like typical positive radical ions and show losses of small molecules and radicals (Figure 4). Thus, the $[\mathrm{CA}]^{+}{ }^{\bullet}$ ion from IL 2, $\mathrm{m} / \mathrm{z} 229$, undergoes $\mathrm{H}^{\bullet}$ loss to form [CA $\mathrm{H}]^{+}, m / z 228$, as the most abundant fragment ion besides losses of other small radicals such as $\mathrm{CH}_{3}{ }^{\circ}$, $\mathrm{CN}^{*}$, and $\mathrm{C}_{2} \mathrm{H}_{5}{ }^{\circ}$, yielding the ions at $\mathrm{m} / \mathrm{z} 213,203$, and 200 , respectively. Furthermore, a rearrangement leads to elimination of $\mathrm{HC}(\mathrm{CN})_{3}$, the protonated anion, causing a prominent fragment ion peak at $\mathrm{m} / \mathrm{z} 137$.

\section{Conclusion}

FI-MS allows the generation of "molecular ions" of ILs in the gas phase, which presents further support for the assumption that neutral ion pairs are formed upon evaporation of ILs. In principle, [CA $]^{+\bullet}$ ions should also be obtained with other ionization techniques capable of soft electron abstraction. The opposite way-i.e., electron capture of the cation and subsequent formation of radical anions-however, should be ruled out because the exothermicity of the neutralization would be accompanied by an excitation of the ion that is far too high.

\section{Supplementary Material}

Additional full-scan FI mass spectra and other material omitted from the print version of this work plus additional tandem mass spectra of selected $\mathrm{C}^{+},[\mathrm{CA}]^{+} \cdot$ ions are available as supplementary material.

\section{Acknowledgments}

The author gratefully acknowledges the gift of ionic liquids from Dr. W.-R. Pitner (Merck KGaA, Darmstadt, Germany), support with respect to FI and FD from Dr. H. B. Linden (Linden CMS, Leeste, Germany), and finally ion source cleaning by colleagues A. Seith and N. Nieth.

\section{References}

1. Wasserscheid, P.; Keim, W. Ionic Liquids-New "Solutions" for Transition Metal Catalysis. Angew. Chem. Int. Ed. 2000, 39, 3772-3789.

2. Brennecke, J. F.; Maginn, E. J. Ionic Liquids: Innovative Fluids for Chemical Processing. AIChE J. 2001, 47, 2384-2389.

3. Chiappe, C.; Pieraccini, D. Ionic Liquids: Solvent Properties and Organic Reactivity. J. Phys. Org. Chem. 2005, 18, 275-297.

4. El Seoud, O. A.; Koschella, A.; Fidale, L. C.; Dorn, S.; Heinze, T. Applications of Ionic Liquids in Carbohydrate Chemistry: A Window of Opportunities. Biomacromolecules 2007, 8, 2629-2647.

5. Pole, C. F. Applications of Ionic Liquids in Extraction, Chromatography, and Electrophoresis. Adv. Chromatogr. 2007, 45, 89-124.

6. Wasserscheid, P.; Welton, T., editors. Ionic Liquids in Synthesis, Vols. 1 and 2, 2nd Ed. Wiley-VCH: Weinheim, Germany; 2007.

7. Earle, M. J.; Esperança, J. M. S. S.; Gilea, M. A.; Canongia Lopez, J. N. Rebelo, L. P. N.; Magee, J. W.; Seddon, K. R.; Widegren, J. A. The Distillation and Volatility of Ionic Liquids. Nature 2006, 439, 831-834.

8. Wasserscheid, P. Chemistry: Volatile Times for Ionic Liquids. Nature 2006, 439, 797. 
9. Ludwig, R.; Kragl, U. Do We Understand the Volatility of Ionic Liquids? Angew. Chem. Int. Ed. 2007, 46, 6582-6584.

10. Armstrong, J. P.; Hurst, C.; Jones, R. G.; Licence, P.; Lovelock, K. R. J.; Satterley, C. J.; Villar-Garcia, I. J. Vapourization of Ionic Liquids. Phys. Chem. Chem. Phys. 2007, 9, 982-990.

11. Leal, J. P.; Esperança, J. M. S. S.; Minas da Piedade, M. E.; Canongia Lopez, J. N.; Rebelo, L. P. N.; Seddon, K. R. The Nature of Ionic Liquids in the Gas Phase. J. Phys. Chem. A. 2007, 111, 6176-6182.

12. DaSilveira, B. A.; Santos, L. S.; Nachtigall, F. M.; Eberlin, M. N.; Dupont, $\mathrm{J}$. On the Species Involved in the Vaporization of Imidazolium Ionic Liquids in a Steam-Distillation-Like Process. Angezw. Chem. Int. Ed. 2006, $45,7251-7254$

13. Abdul-Sada, A. K.; Elaiwi, E. A.; Greenway, A. M. Evidence for the Clustering of Substituted Imidazolium Salts via Hydrogen Bonding Under the Conditions of Fast Atom Bombardment Mass Spectrometry. Eur. Mass Spectrom. 1997, 3, 245-247.

14. Zabet-Moghaddam, M.; Krueger, R. Heinzle, E.; Tholey, A. MatrixAssisted Laser Desorption/Ionization Mass Spectrometry for the Characterization of Ionic Liquids and the Analysis of Amino Acids, Peptides and Proteins in Ionic Liquids. J. Mass Spectrom. 2004, 39, 1494-1505.

15. Zabet-Moghaddam, M.; Heinzle, E.; Tholey, A. Qualitative and Quantitative Analysis of Low Molecular Weight Compounds by Ultraviolet Matrix-Assisted Laser Desorption/Ionization Mass Spectrometry Using Ionic Liquid Matrices. Rapid Commun. Mass Spectrom. 2004, 18, 141-148.

16. Tholey, A.; Heinzle, E. Ionic (Liquid) Matrices for Matrix-Assisted Laser Desorption/Ionization Mass Spectrometry-Applications and Perspectives. Anal. Bioanal. Chem. 2006, 386, 24-37.

17. Dyson, P. J.; Khalaila, I.; Luettgen, S.; McIndoe, J. S.; Zhao, D. Direct Probe Electrospray (and Nanospray) Ionization Mass Spectrometry of Neat Ionic Liquids. Chem. Commun. 2004, 5, 2204-2205.

18. Jackson, G. P.; Duckworth, D. C. Electrospray Mass Spectrometry of Undiluted Ionic Liquids. Chem. Commun. 2004, 5, 522-523.

19. Zhao, D. Analysis of Ionic Liquids and Dissolved Species by Electrospray Ionization MS. Aust. J. Chem. 2004, 57, 509.

20. Milman, B. L.; Alfassi, Z. B. Detection and Identification of Cations and Anions of Ionic Liquids by Means of Electrospray Ionization Mass
Spectrometry and Tandem Mass Spectrometry. Eur. J. Mass Spectrom. 2005, 11, 35-42.

21. Gross, J. H. Liquid Injection Field Desorption/Ionization Mass Spectrometry of Ionic Liquids. J. Am. Chem. Soc. Mass Spectrom. 2007, 18 2254-2262

22. Gomer, R.; Inghram, M. G. Applications of Field Ionization to Mass Spectrometry. J. Am. Chem. Soc. 1955, 77, 500.

23. Beckey, H. D. Field-Ionization Mass Spectrometry, 1st edition. Pergamon: Elmsford, NY; 1971.

24. Beckey, H. D.; Schulten, H.-R. Field Desorption Mass Spectrometry Angew. Chem. 1975, 87, 425-438.

25. Beckey, H. D. Principles of Field Desorption and Field Ionization Mass Spectrometry, 1st edition. Pergamon: Oxford, UK; 1977.

26. Prókai, L. Field Desorption Mass Spectrometry, 1st edition. Marcel Dekker: New York; 1990.

27. Linden, H. B. Liquid Injection Field Desorption Ionization: A New Too for Soft Ionization of Samples Including Air-Sensitive Catalysts and Non-Polar Hydrocarbons. Eur. J. Mass Spectrom. 2004, 10, 459-468.

28. Beckey, H. D.; Schulze, P. Field Ionization Mass Spectra of Organic Molecules. III. N-Paraffins Up to $\mathrm{C}_{16}$ and Branched Paraffins. Z Naturforsch. 1965, 20A, 1329-1335.

29. Gross, J. H.; Weidner, S. M. Influence of Electric Field Strength and Emitter Temperature on Dehydrogenation and C-C Cleavage in Field Desorption Mass Spectrometry of Polyethylene Oligomers. Eur. J. Mass Spectrom. 2000, 6, 11-17.

30. Gross, J. H.; Vékey, K.; Dallos, A. Field Desorption Mass Spectrometry of Large Multiply Branched Saturated Hydrocarbons. J. Mass Spectrom. 2001, 36, 522-528.

31. Hammerum, S. Distonic Radical Cations in the Gaseous and Condensed Phase. Mass Spectrom. Rev. 1988, 7, 123-202.

32. Stirk, K. M.; Kiminkinen, M. L. K.; Kenttämaa, H. I. Ion-Molecule Reactions of Distonic Radical Cations. Chem. Rev, 1992, 92, 1649-1665.

33. Zappey, H. W.; Ingemann, S.; Nibbering, N. M. M. Isomerization and Fragmentation of Aliphatic Thioether Radical Cations in the Gas Phase: Ion-Neutral Complexes in the Reactions of Metastable Ethyl Propyl Thioether Ions. J. Chem. Soc. Perkin Trans. 1991, 2, 1887-1892. 